\title{
Effect of estradiol, progesterone and testosterone on apoptosis- and proliferation-induced MAPK signaling in human umbilical vein endothelial cells
}

\author{
YANINA POWAZNIAK, ANA CATALINA KEMPFER, MARÍA DE LA PAZ DOMINGUEZ, CRISTINA FARIAS, \\ LETICIA KELLER, JULIO CESAR CALDERAZZO and MARIA ANGELA LAZZARI
}

CONICET, Instituto de Investigaciones Hematologicas, Academia Nacional de Medicina de Buenos Aires, Pacheco de Melo 3081 (C1425AUM), Buenos Aires, Argentina

Received September 17, 2008; Accepted January 7, 2009

DOI: $10.3892 / \mathrm{mmr}+00000119$

\begin{abstract}
Sex hormones induce death or cell proliferation in various cell lines and in primary cultures. However, the signal transduction pathways involved in the regulation of proliferation and apoptosis in endothelial cells have not been fully elucidated. Here, we report that progesterone and testosterone induce apoptosis in HUVECs in a p38- and JNK-dependent manner, and that estradiol promotes proliferation via the activation of ERK2. We showed that, at physiological doses, progesterone and testosterone promoted p38, but not JNK, phosphorylation. Hormone inhibitors, on the other hand, prevented p38 phosphorylation. When supraphysiological doses were applied, both p38 and JNK were phosphorylated, causing apoptotic cell death. The addition of hormone inhibitors at an appropriate concentration did not prevent cell death or the phosphorylation of p38 and JNK. Estradiol, at physiological doses, promoted an increase in ERK2 phosphorylation that was blocked by fulvestrant. At physiological and supraphysiological doses, it promoted a proliferative effect. In conclusion, these findings suggest that JNK has an important pro-apoptotic function following progesterone and testosterone treatment in human endothelial cells, and that ERK2 has a proliferative effect following estradiol treatment.
\end{abstract}

\section{Introduction}

Apoptosis seems to be the main mechanism of death of the endothelium under physiological conditions. Moreover, the balance between proliferation and apoptosis in endothelial cells plays a critical role in the formation and regression of blood

Correspondence to: Dr Yanina Powazniak, CONICET, Instituto de Investigaciones Hematologicas, Academia Nacional de Medicina de Buenos Aires, Pacheco de Melo 3081 (C1425AUM), Buenos Aires, Argentina

E-mail: ypowazniak@hematologia.anm.edu.ar yaninapowazniak@gmail.com

Key words: testosterone, progesterone, estradiol, extracellular regulated kinase1/2, p38, Jun N-terminal kinase, apoptosis, proliferation, phosphorylation vessels, especially the arterioles and capillaries. Therefore, excessive apoptosis in endothelial cells may be involved in both endothelial dysfunctions and in the inhibition of angiogenesis, as described in various vascular diseases (1-3).

Hormone concentrations are subject to strict regulation to ensure that an unbalance in hormone secretion, resulting in the loss of cellular homeostasis, does not occur. Under certain circumstances, certain hormones act to stimulate cell proliferation $(4,5)$.

Mitogen-activated protein kinases (MAPKs) are serine/ threonine-specific protein kinases that respond to extracellular stimuli (mitogens) and regulate various cellular activities, such as gene expression, mitosis, differentiation and cell survival/ apoptosis. The extracellular regulated kinase (ERK)1/2 MAPK pathway consists of a protein kinase cascade linking growth and differentiation signals (6). p38 and Jun N-terminal (JNK) are members of the stress-activated MAP kinases, and their activation has been implicated in various forms of apoptosis $(7,8)$. Estradiol, progesterone, and testosterone can act nongenomically via membrane-associated receptors to activate MAPKs, as can various other ligands acting through heterotrimeric $\mathrm{G}$ protein receptors (9-11). The purpose of this study was to determine whether the hormones present in normal human plasma have an effect on the MAPK signaling pathway in human umbilical vein endothelial cells (HUVECs), and to establish their role in the balance between proliferation and apoptosis. We therefore investigated the effects of estradiol, progesterone and testosterone on the activation of MAPKs in HUVECs to fully understand the intracellular signaling response to these hormones.

\section{Materials and methods}

Sample collection. Blood was collected using siliconized vacutainer tubes containing $1 / 10$ volume $3.8 \%$ trisodium citrate $2 \mathrm{H}_{2} \mathrm{O}$. The tubes were then centrifuged twice at $1500 \mathrm{x} \mathrm{g}$ for $25 \mathrm{~min}$ at room temperature. The plasma was separated, placed in pyrogen-free microcentrifuge tubes, immediately frozen and stored at $-80^{\circ} \mathrm{C}$ until use.

Cell culture and treatments. HUVECs were isolated from normal pregnancies with $0.1 \%$ collagenase type 1 (12). Cells were cultured in RPMI-1640 medium (Gibco, Scotland) 
A

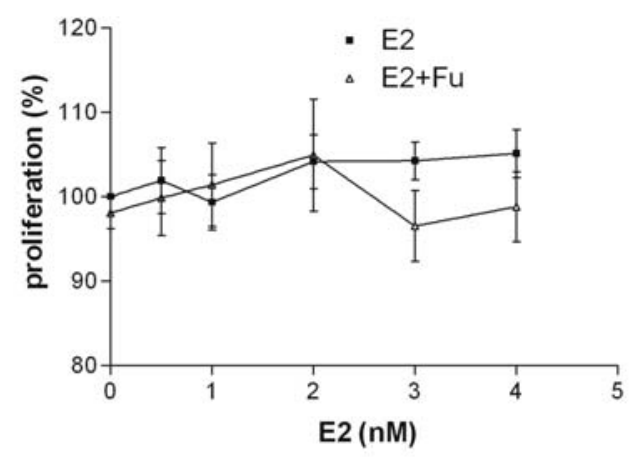

C

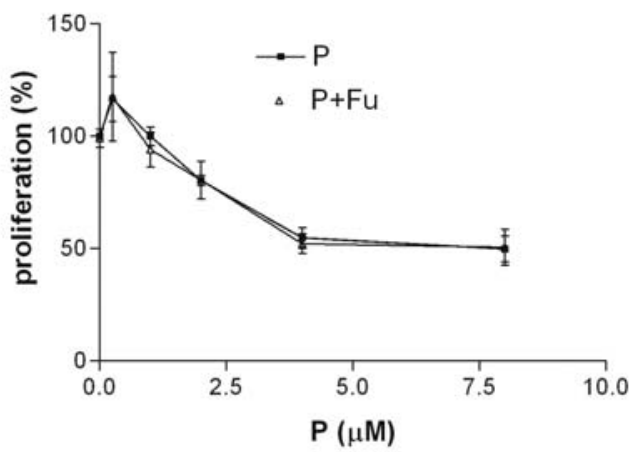

$E$

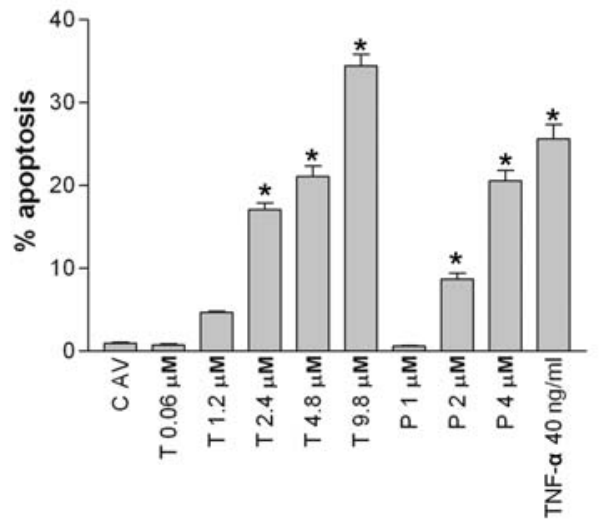

B

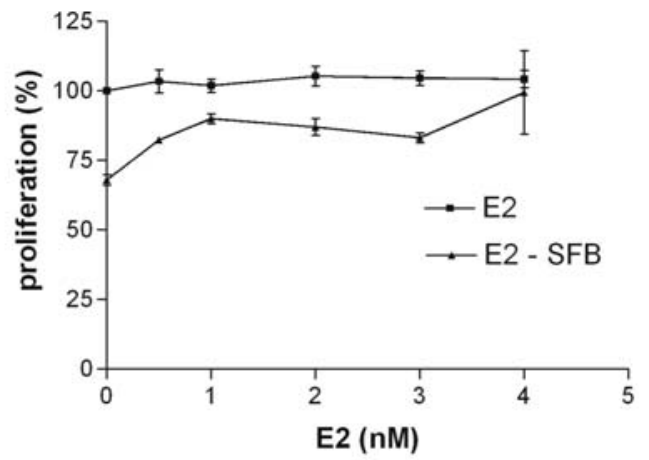

D

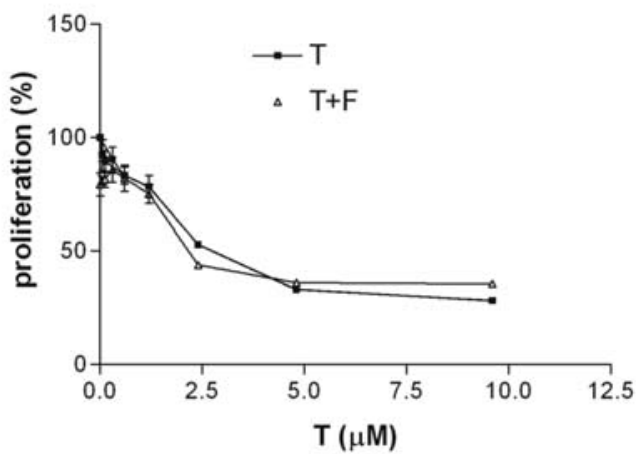

Figure 1. 17ß-estradiol (E2) promotes cell survival. Testosterone (T) and progesterone $(\mathrm{P})$ promote cell death and apoptosis in HUVECs at nonphysiological doses. To evaluate the growth inhibitory effect of $\mathrm{T}$ and $\mathrm{P}$ on HUVECs, the MTS assay was used. Data are reported as the means \pm SD. The OD of control samples was regarded as 100 . Each condition was performed with 4 wells. The results are reported as the means \pm SD of 4 separate experiments, with $\mathrm{p} \leq 0.05$ as determined by ANOVA. Cells were stimulated with (A) E2, E2+fulvestrant (Fu), (B) E2, E2+starvation (SFB), (C) P, P+Fu, (D) T, T+flutamide (F). (E) The apoptosis of HUVECs stimulated by normal male plasma, normal female plasma, normal female plasma-pregnant, E2, T or P. After stimulation, cells were harvested and the percentage of apoptotic cells was measured by flow cytometric analysis. The results are the means \pm SD of 3 separate experiments. ${ }^{*} \mathrm{p} \leq 0.05$ as determined by ANOVA. supplemented with endothelial cell growth factor (Sigma, St. Louis, MO, USA), L-glutamine, 2-mercaptoethanol, heparin, penicillin and streptomycin, and $10 \%$ fetal bovine serum (FBS; Gibco), then incubated at $37^{\circ} \mathrm{C}, 5 \% \mathrm{CO}_{2}$ in a humidified incubator. Cells from different umbilical cords were mixed and used to test hormones. HUVECs were used between passages three and six.

Cells were cultured in 6-well dishes until $80 \%$ confluence was attained. Before exposure to the HUVECs, the plasma was heparinized $(100 \mu \mathrm{g} / \mathrm{ml})$ to prevent clotting of the dilute sodium citrate plasma. It was then added to the cultured HUVECs at a final concentration of $10 \%$ plasma. The cells were treated with normal male plasma (NMP), normal female plasma (NFP) and normal female plasma from pregnant women (NFP-p), as well as 17ß-estradiol (E2) (Sigma), progesterone (P) (Sigma), testosterone (T) (Sigma) or vehicle (control). Hormone concentrations were as follows: physio- logical, $0.06 \mu \mathrm{M}$ T, $1 \mathrm{nM} \mathrm{E2,} 1 \mu \mathrm{M} \mathrm{P}$; and supraphysiological, 0.12-9.6 $\mu \mathrm{M}$ T, 2-8 nM E2, 2-8 $\mu \mathrm{M}$ P. We respectively used fulvestrant (Fu) (Sigma) and flutamide (F) (Sigma) as the hormone antagonists of $\mathrm{E} 2$ and $\mathrm{P}$ and $\mathrm{T}$. To determine the effectiveness of $\mathrm{Fu}$ and $\mathrm{F}$ in inhibiting the effects of $\mathrm{E} 2, \mathrm{P}$ and $\mathrm{T}$, we pretreated HUVECs with $\mathrm{Fu}(10 \mathrm{nM}-80 \mu \mathrm{M})$ or $\mathrm{F}$ (1-10 $\mu \mathrm{M})$ for $30 \mathrm{~min}$, then stimulated the cells with $\mathrm{E} 2, \mathrm{P}$ or $\mathrm{T}$ for $60 \mathrm{~min}$. TNF- $\alpha(40 \mathrm{ng} / \mathrm{ml})$ was used as a positive control for apoptosis.

Cell proliferation assay. HUVECs were seeded at a density of 5000 cells/well in a gelatin-coated tissue culture plate. Twelve hours after seeding, the HUVECs were treated. Cell proliferation was measured using the MTS proliferation assay (Promega, WI) at $48 \mathrm{~h}$ post treatment. The test protocol for cytotoxicity evaluation was adopted from previously published studies $(13,14)$. After completion of the exposure period, the 
Table I. Statistical analysis of ERK1/2 phosphorylation in HUVECs incubated with NMP, NFP, NFP-p, E2, P and T.

\begin{tabular}{lccccccr}
\hline & \multicolumn{3}{c}{ p-ERK1 } & & \multicolumn{3}{c}{ p-ERK2 } \\
\cline { 2 - 3 } \cline { 6 - 7 } & Mean & SD & p-value & & Mean & SD & p-value \\
\hline C & 0.8 & 0.21 & & 0.7 & 0.19 & \\
NFP & 0.8 & 0.17 & 1.000 & & 0.5 & 0.17 & 0.246 \\
NMP & 0.6 & 0.17 & 0.288 & & 0.6 & 0.27 & 0.628 \\
NFP-p & 0.6 & 0.26 & 0.391 & & 0.8 & 0.13 & 0.494 \\
E2 & 0.6 & 0.15 & 0.268 & & 1.8 & 0.10 & $<0.050$ \\
E2+F & 0.6 & 0.17 & 0.269 & & 0.7 & 0.04 & 1.000 \\
T & 1.0 & 0.30 & 0.398 & & 1.0 & 0.27 & 0.191 \\
P & 0.6 & 0.20 & 0.298 & & 0.6 & 0.17 & 0.534 \\
\hline ANOVA & & & & & & &
\end{tabular}

ANOVA relative to respective control; post-hoc test, Student-NewmanKeul test. $\mathrm{p} \leq 0.05$ was considered significant. C, control; NMP, normal male plasma; NFP, normal female plasma; NFP-p, normal female plasma-pregnant, E2, 17ß-estradiol; T, testosterone; $\mathrm{P}$, progesterone; F, flutamide.

absorbance of the formazan product was read at $492 \mathrm{~nm}$. Two internal controls were set up for each experiment consisting of cells only and medium only. Background absorbance due to non-specific reactions between test compounds and the MTS reagent was deducted from exposed cell values.

Apoptosis assay by flow cytometry. Annexin V is a calciumdependent phospholipid-binding protein with a high affinity for phosphatidylserine in the plasma membrane (15) and is used, as in this study, for the analysis of apoptotic damage in HUVECs. Subconfluent HUVECs were treated for $48 \mathrm{~h}$ in a humidified incubator. Treated cells were harvested, washed and labeled with Annexin V-FITC and propidium iodide apoptosis kits (Calbiochem, Darmstadt). The cells were analyzed using the Beckton Dickinson FACScan flow cytometer with a commercially available software program (CellQuest).

Western blot analysis. HUVECs were starved of FBS for $6 \mathrm{~h}$ and then treated for $1 \mathrm{~h}$ at $37^{\circ} \mathrm{C}$. Cells were washed once with ice-cold PBS and immediately lysed by the addition of boiling Laemmli sample buffer (16). Proteins were subjected to electrophoresis in $12 \%$ SDS-PAGE and transferred to a nitrocellulose membrane. The mouse monoclonal antibodies Phospho Detect anti-ERK1/2 kinase and anti- $\beta$-actin were from Sigma. The rabbit monoclonal antibodies used were the Phospho Detect anti-p38 MAPK (Calbiochem, Darmstadt) and the anti-JNK activated (diphosphorylated JNK) clone JNK-PT48 (Sigma). The secondary antibodies used were horseradish peroxidase-conjugated anti-rabbit or anti-mouse antibodies (Sigma). Blots were visualized using ECL Western blotting detection reagents (Sigma) and X-ray film. Images were scanned and quantified using Image Master 1D (Pharmacia). The intensity values obtained from the software were related to the $B$-actin value of each band. The final number for each sample was then statistically analyzed.

Statistical analysis. Differences between the results of experimental treatments were evaluated by ANOVA and post-hoc
A

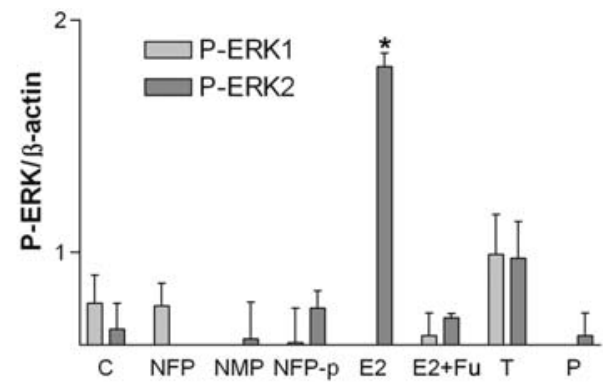

B

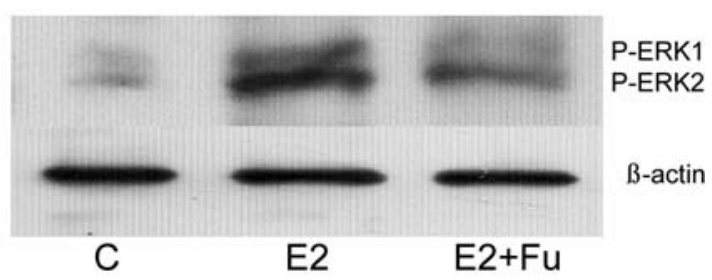

Figure 2. 17ß-estradiol (E2)-induced ERK2 phosphorylation. Amount of phosphorylated ERK1/2 MAPK in cytosolic extracts from HUVECs. Cells untreated (C) or treated with normal male plasma (NMP), normal female plasma (NFP), normal female plasma-pregnant (NFP-p), E2, E2+fulvestrant $(\mathrm{Fu})$, testosterone $(\mathrm{T})$ or progesterone $(\mathrm{P})$ for $1 \mathrm{~h}$ were analyzed by immunoblotting for changes in the phosphorylation of ERK1/2. Lysates from HUVECs were probed with a phospho-specific ERK1/2 antibody and then reprobed for B-actin. (A) Anti-phospho-MAPK Western blot densitometric analysis. Relative amounts of phospho-ERK1/2 were obtained by normalizing against $\beta$-actin. Data are represented as the fold increase in the phosphorylated form relative to $B$-actin levels. The results are the means \pm SD of 3 separate experiments. "p $\leq 0.05$ as determined by ANOVA. (B) Representative Western blot analysis of cytosolic lysates.

testing using the Student-Newman-Keul test. $\mathrm{p} \leq 0.05$ was considered significant.

\section{Results}

$17 \beta$ estradiol promotes cell survival induced by the deprivation of serum and activates the ERK2 pathway. The results for E2 are shown in Fig. 1A and B, which represents the cell response to increasing concentrations of E2 (0.5-4 nM). Fig. 1A shows that different concentrations of E2 did not promote cell survival, and that neither did the addition of Fu. When cells were starved, E2 treatment resulted in significant differences without FBS (Fig. 1B).

Using different systems, it has been demonstrated that the mitogenic effect of E2 requires the activation of the ERK cascade. To examine this, we tested whether incubating HUVECs with E2 increased ERK1/2 phosphorylation. Fig. 2 shows that there was a significant increase $(p<0.05)$ in ERK2 phosphorylation after $1 \mathrm{~h}$ of stimulation with E2. However, a significant increase in phosphorylated ERK1 was not found (Fig. 2B). Fig. 2B shows that incubation with Fu reversed the E2-induced phosphorylation of ERK2. There was no significant difference between HUVECs treated with NFP, NFP-p, NMP or the control (Fig. 2A, Table I).

Progesterone and testosterone induce apoptosis in HUVECs and promote $\mathrm{p} 38$ and JNK phosphorylation. The MTS assay showed an inhibition of cell growth after the addition of 
A

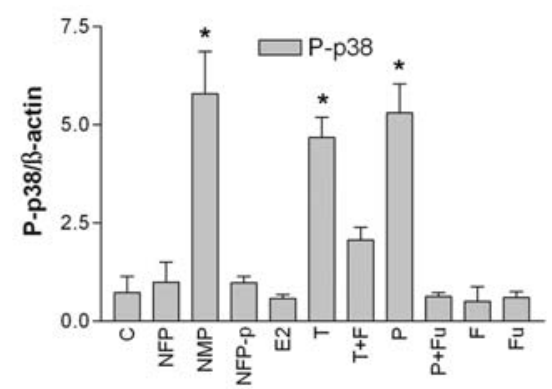

C

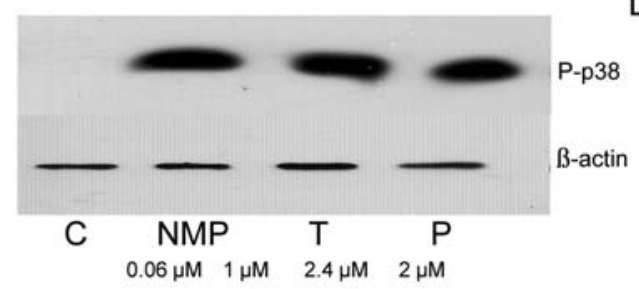

E

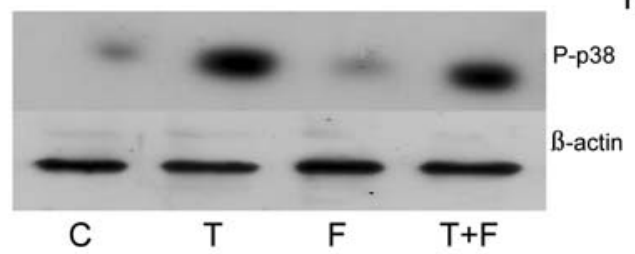

G

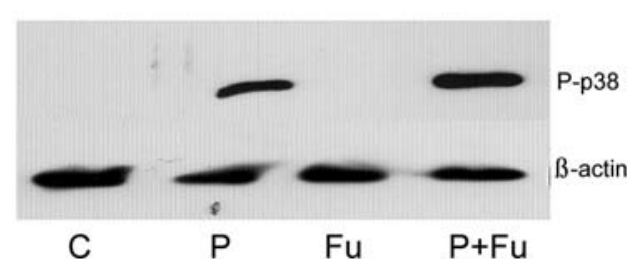

B
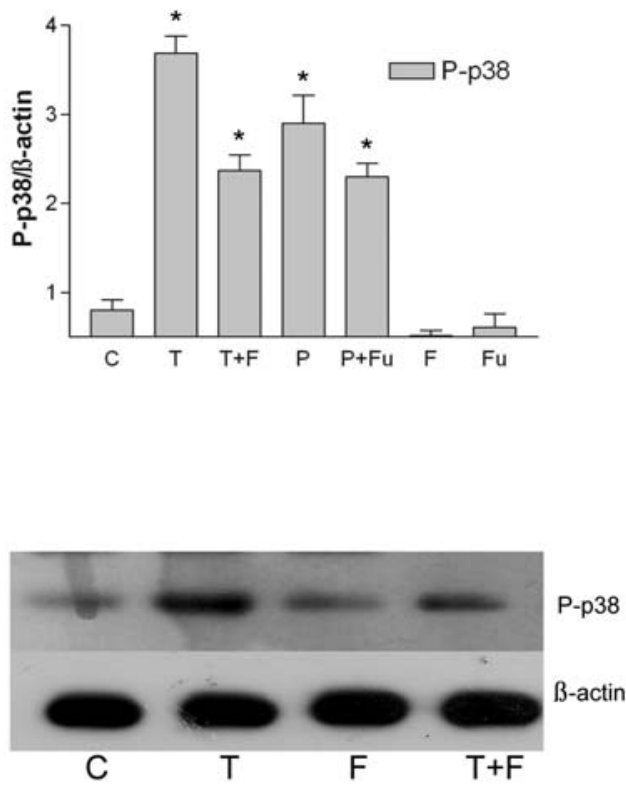

$\mathrm{F}$

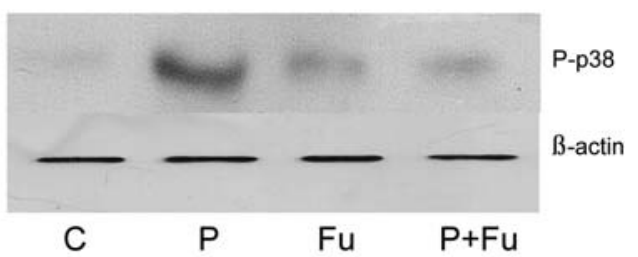

C

$\mathrm{P}$

Fu

Figure 3. Normal male plasma (NMP), testosterone (T)- and progesterone (P)-induced p38 phosphorylation. The amount of phosphorylated p-38 MAPK in cytosolic extracts from HUVECs. (A) Cells untreated (C) or treated with NMP, normal female plasma (NFP), NFP-pregnant (NFP-p), 17ß-estradiol (E2), T, $\mathrm{T}+$ flutamide $(\mathrm{F}), \mathrm{P}$ and $\mathrm{P}+$ fulvestrant $(\mathrm{Fu})$ for $1 \mathrm{~h}$ were analyzed by immunoblotting for changes in the phosphorylation of $\mathrm{p} 38$. $\mathrm{T}$ and $\mathrm{P}$ concentrations were physiological. Lysates from HUVECs were probed with a phospho-specific p38 antibody, and then the blot was reprobed for B-actin. Anti-phospho-MAPK Western blot densitometric analysis. Relative amounts of phospho-p38 were obtained by normalizing against $B$-actin. Data are represented as the fold increase in the phosphorylated form relative to $ß$-actin levels. The results are the means \pm SD of 3 separate experiments, ${ }^{*} \mathrm{p} \leq 0.05$ (treatments vs. control) as determined by ANOVA. (B) Cells untreated or treated with $\mathrm{T}, \mathrm{T}+\mathrm{F}, \mathrm{P}$ and $\mathrm{P}+\mathrm{Fu}$ for $1 \mathrm{~h}$ were analyzed by immunoblotting for changes in the phosphorylation of $\mathrm{p} 38$. T and $\mathrm{P}$ concentrations were non-physiological. Representative Western blot analysis of cytosolic lysates. HUVECs treated with (C) NMP, T and P (physiological concentrations), (D) $\mathrm{T}$ and $\mathrm{T}+\mathrm{F}$ (physiological concentrations), (E) $\mathrm{T}$ and $\mathrm{T}+\mathrm{F}$ (non-physiological concentrations), (F) $\mathrm{P}$ and $\mathrm{P}+\mathrm{Fu}$ (physiological concentrations), (G) $\mathrm{P}$ and $\mathrm{P}+\mathrm{Fu}$ (non-physiological concentrations).

increasing concentrations of $\mathrm{P}(0.3-8 \mu \mathrm{M})$ (Fig. 1C). The use of physiological concentrations of $\mathrm{P}$ did not produce a change in cell viability, although exposure to supraphysiological concentrations induced a significant decrease $(\mathrm{p}<0.05)$ in cell survival $(80 \pm 4$ to $52 \pm 11 \%)$. Fig. 1D shows the change in cell viability with increasing $\mathrm{T}$ concentrations $(0.3-9.6 \mu \mathrm{M})$. Incubation with $\mathrm{T}(75 \pm 12$ to $28 \pm 19 \%$ cell survival) produced the same inhibition of cell growth as treatment with P.

Since the MTS test does not discriminate between necrosis or apoptosis, the Annexin V/IP test by flow cytometry was performed. Treatment for 24 and $48 \mathrm{~h}$ with $\mathrm{P}$ and $\mathrm{T}$ at supra- physiological doses and TNF- $\alpha$ as a control resulted in a significant increase $(\mathrm{p}<0.05)$ in apoptosis (Fig. 2, Table I). There was a significant increase $(\mathrm{p}<0.05)$ in the percentage of apoptosis in cells treated with $2 \mu \mathrm{M}(8 \pm 1 \%)$ and $4 \mu \mathrm{M}$ $(20 \pm 2 \%) \mathrm{P}$. Cells treated with $1 \mu \mathrm{M}$ P did not differ significantly from the controls. When HUVECs were exposed to $0.06 \mu \mathrm{M}$ T for $24 \mathrm{~h}$, a low number of Annexin V-positive cells were detected. When supraphysiological concentrations were used, the Annexin V-positive cells increased significantly $(\mathrm{p}<0.05$ ), from $21 \pm 2 \%$ to $4.8 \mu \mathrm{M}$ and $34 \pm 2 \%$ to $9.8 \mu \mathrm{M}$ (Fig. 1, Table II). 
A

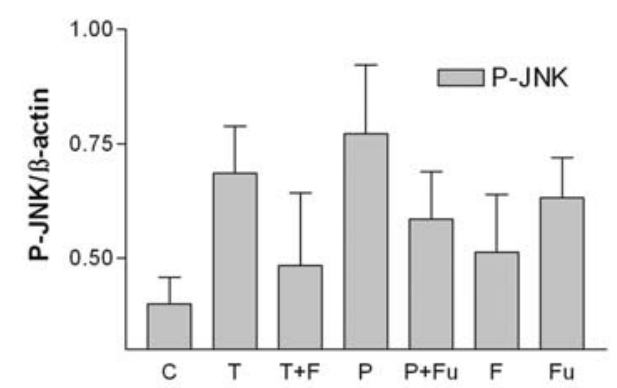

B

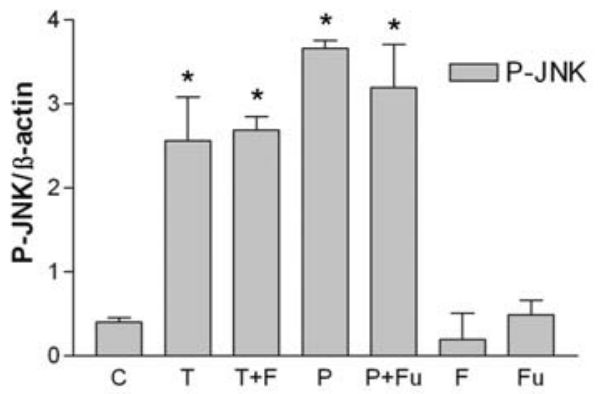

C

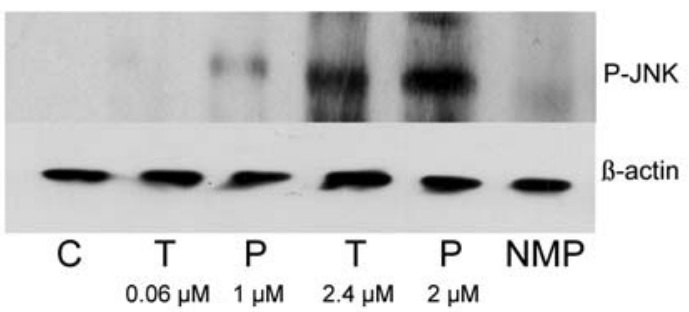

Figure 4. Testosterone (T)- and progesterone (P)-induced JNK phosphorylation at non-physiological doses. The amount of phosphorylated JNK MAPK in cytosolic extracts from HUVECs. Cells untreated (C) or treated with normal male plasma (NMP), T, T+ flutamide (F), P and P+ fulvestant (Fu) for $1 \mathrm{~h}$ were analyzed by immunoblotting for changes in the phosphorylation of JNK. T and P concentrations were physiological and non-physiological. Lysates from HUVECs were probed with a phospho-specific JNK antibody, and then the blot was reprobed for B-actin. Anti-phospho-MAPK Western blot densitometric analysis. Relative amounts of phospho-JNK were obtained by normalizing against B-actin. Data are represented as the fold increase in the phosphorylated form relative to $\beta$-actin levels. The results are the means $\pm \mathrm{SD}$ of 3 separate experiments. ${ }^{*} \mathrm{p} \leq 0.05$ (treatments vs. control) as determined by ANOVA. (A) physiological doses. (B) Supraphysiological doses. (C) Representative Western blot analysis of cytosolic lysates. HUVECs treated with NMP, T and P at physiological doses $(0.06 \mu \mathrm{M} \mathrm{T}, 1 \mu \mathrm{M} \mathrm{P})$ and supraphysiological doses $(2.4 \mu \mathrm{M} \mathrm{T}, 2 \mu \mathrm{M} \mathrm{P})$.

To study the possible action of p38 as an intermediary in apoptotic signaling in HUVECs, we carried out two runs using $\mathrm{P}$ and $\mathrm{T}$ in physiological and supraphysiological concentrations.

Table II. Statistical analysis of apoptotic percentages in HUVECs incubated with NMP, NFP, NFP-p, E2, T, P and TNF- $\alpha$.

\begin{tabular}{lrrr}
\hline & Mean & SD & p-value \\
\hline C Annexin V/IP & 0.96 & 0.21 & $<0.050$ \\
E2 $(1 \mathrm{nM})$ & 1.09 & 0.18 & 0.460 \\
$\mathrm{P}(1 \mu \mathrm{M})$ & 0.63 & 0.17 & 0.102 \\
$\mathrm{P}(2 \mu \mathrm{M})$ & 8.70 & 1.24 & $<0.050$ \\
$\mathrm{P}(4 \mu \mathrm{M})$ & 20.56 & 2.20 & $<0.050$ \\
NMP & 0.79 & 0.13 & 0.299 \\
NFP & 0.63 & 0.24 & 0.148 \\
NFP-p & 0.42 & 0.16 & 0.069 \\
$\mathrm{~T}(0.06 \mu \mathrm{M})$ & 0.79 & 0.13 & 0.269 \\
$\mathrm{~T}(1.2 \mu \mathrm{M})$ & 4.73 & 0.16 & $<0.050$ \\
$\mathrm{~T}(2.4 \mu \mathrm{M})$ & 17.07 & 1.39 & $<0.050$ \\
$\mathrm{~T}(4.8 \mu \mathrm{M})$ & 21.13 & 2.13 & $<0.050$ \\
$\mathrm{~T}(9.8 \mu \mathrm{M})$ & 34.45 & 2.38 & $<0.050$ \\
TNF- $\alpha(40 \mathrm{ng} / \mathrm{ml})$ & 25.65 & 2.98 & $<0.050$ \\
\hline
\end{tabular}

ANOVA relative to respective control; post-hoc test, Student-NewmanKeul. $\mathrm{p} \leq 0.05$ was considered significant. $\mathrm{C}$, control; NMP, normal male plasma; NFP, normal female plasma; NFP-p, normal female plasmapregnant; E2, 17ß-estradiol; P, progesterone; T, testosterone.
We found that regardless of the dose used, $\mathrm{P}$ and $\mathrm{T}$ produced a significant increase $(\mathrm{p}<0.05)$ in $\mathrm{p} 38$ phosphorylation (Fig. 3A, $\mathrm{B}, \mathrm{D}$ and $\mathrm{G})$. Inhibitors for $\mathrm{P}$ and $\mathrm{T}$ reversed the effect of the increased phosphorylation of $\mathrm{p} 38$ when physiological concentrations were used, but neither Fu nor $\mathrm{F}$ was able to reverse the effect at supraphysiological concentrations (Fig. 3A, B, D and G). It was noted that, at supraphysiological concentrations, $\mathrm{P}$ and $\mathrm{T}$ significantly increased $(\mathrm{p}<0.05) \mathrm{JNK}$ phosphorylation (Fig. 4B and C). Furthermore, it was observed that hormones at physiological concentrations were not able to activate JNK (Fig. 4A and C). Inhibitors of $\mathrm{P}$ and $\mathrm{T}$ were able to reverse the effects of JNK phosphorylation when hormones were used at physiological, but not supraphysiological, concentrations. All phosphorylation differences were verified by an average of the intensities of pixels (Tables III and IV). There was no significant difference in the phosphorylation of ERK1/2 in HUVECs treated with NMP, T, P or the control. (Fig. 2A, Table II).

\section{Discussion}

In recent years, there have been numerous symptoms and side effects associated with an imbalance in estrogen-androgen levels. On the one hand, declining levels of androgens in women leading to a predominance of estrogens has been linked to the emergence of numerous side effects, including an increased incidence of gynaecological tumours. At the other extreme, we identified several situations in which the imbalance favored androgens, which reached supranormal levels (hormone replacement therapy, trans male-to-female sexuality). These high levels of androgens have also been correlated with the occurrence of adverse effects on the female 
Table III. Statistical analysis of the phosphorylation of p38 in HUVECs incubated with NMP, NFP, NFP-p, E2, P and T.

A. Phosphorylation of p38 at physiological doses.

\begin{tabular}{lccr}
\hline & Mean & SD & p-value \\
\hline C & 0.6 & 0.90 & \\
NMP & 1.0 & 0.90 & 0.615 \\
NFP & 5.8 & 1.86 & $<0.050$ \\
NFP-p & 1.0 & 0.27 & 0.502 \\
E2 & 0.6 & 0.15 & 1.000 \\
T & 4.7 & 0.89 & $<0.050$ \\
T+F & 2.1 & 0.55 & 0.190 \\
P & 5.3 & 1.29 & $<0.050$ \\
P+Fu & 0.6 & 0.17 & 1.000 \\
F & 0.3 & 0.89 & 0.702 \\
Fu & 0.6 & 0.26 & 1.000 \\
\hline
\end{tabular}

B. Phosphorylation of p38 at supraphysiological doses.

\begin{tabular}{lccr}
\hline & Mean & SD & p-value \\
\hline $\mathrm{C}$ & 0.8 & 0.20 & \\
$\mathrm{~T}$ & 3.7 & 0.33 & $<0.050$ \\
$\mathrm{~T}+\mathrm{F}$ & 2.4 & 0.31 & $<0.050$ \\
$\mathrm{P}$ & 2.9 & 0.55 & $<0.050$ \\
$\mathrm{P}+\mathrm{Fu}$ & 2.3 & 0.26 & $<0.050$ \\
$\mathrm{~F}$ & 0.5 & 0.10 & 0.081 \\
$\mathrm{Fu}$ & 0.6 & 0.26 & 0.351 \\
\hline
\end{tabular}

ANOVA relative to respective control; post-hoc test, StudentNewman-Keul. $\mathrm{p} \leq 0.05$ was considered significant. C, control; NMP, normal male plasma; NFP, normal female plasma; NFP-p, normal female plasma-pregnant; E2, 17ß-estradiol; T, testosterone; P, progesterone; Fu, fulvestrant; F, flutamide.

reproductive system, including abnormal growth and possible tumorigenic risk.

Kawagoe et al demonstrated that raloxifene, which has vasoprotective actions similar to those of estrogen, provoked an increase in cell proliferation in endothelial cells (17). E2 has been described as promoting the activation of ERK $1 / 2$ in different cell lines and primary cultures (18-20). However, in various experiments with endothelial cells in vitro, E2 has been shown to have opposing effects on signal transduction. Sengupta et al demonstrated that, after a 1-h exposure, E2 caused an increase in the phosphorylation of ERK $1 / 2$ in HUVECs that was sustained for several hours (21). However, Juan et al reported that E2 inhibits the ERK1/2 pathway in endothelial cells (22).

Our results indicate that, at physiological concentrations, E2 has a proliferative effect on HUVECs mediated by the activation of ERK2. This effect was observed during the 1-h incubation period, without any phosphorylation of ERK1. When HUVECs were incubated in complete medium, no significant differences were observed with the addition of E2 at different concentrations. However, when the medium lacked
Table IV. Statistical analysis of phosphorylation of JNK in HUVECs incubated with $\mathrm{P}, \mathrm{P}+\mathrm{Fu}, \mathrm{Fu}, \mathrm{T}, \mathrm{T}+\mathrm{F}$ and $\mathrm{F}$.

A. Phosphorylation of JNK at physiological doses.

\begin{tabular}{lccc}
\hline & Mean & SD & p-value \\
\hline $\mathrm{C}$ & 0.400 & 0.10 & \\
$\mathrm{~T}$ & 0.655 & 0.20 & 0.060 \\
$\mathrm{~T}+\mathrm{F}$ & 0.489 & 0.26 & 0.410 \\
$\mathrm{P}$ & 0.757 & 0.26 & 0.094 \\
$\mathrm{P}+\mathrm{Fu}$ & 0.583 & 0.17 & 0.196 \\
$\mathrm{~F}$ & 0.525 & 0.21 & 0.482 \\
$\mathrm{Fu}$ & 0.627 & 0.17 & 0.154 \\
\hline
\end{tabular}

B. Phosphorylation of JNK at supraphysiological doses.

\begin{tabular}{lccr}
\hline & Mean & SD & p-value \\
\hline $\mathrm{C}$ & 0.406 & 0.10 & \\
$\mathrm{~T}$ & 3.467 & 0.90 & $<0.050$ \\
$\mathrm{~T}+\mathrm{F}$ & 2.964 & 0.27 & $<0.050$ \\
$\mathrm{P}$ & 3.819 & 0.15 & $<0.050$ \\
$\mathrm{P}+\mathrm{Fu}$ & 4.088 & 0.89 & $<0.050$ \\
$\mathrm{~F}$ & 0.743 & 0.55 & 0.312 \\
$\mathrm{Fu}$ & 0.789 & 0.30 & 0.106 \\
\hline
\end{tabular}

ANOVA relative to respective control; post-hoc test, Student-NewmanKeul. $\mathrm{p} \leq 0.05$ was considered significant. $\mathrm{C}$, control; $\mathrm{T}$, testosterone; $\mathrm{P}$, progesterone; $\mathrm{Fu}$, fulvestrant; $\mathrm{F}$, flutamide.

FBS, HUVECs were only able to grow in the presence of E2. These results suggest that $\mathrm{E} 2$ has a proliferative effect on endothelial cell growth, and that activation of the ERK2 pathway may play a role in estrogen-mediated endothelial cell protection.

The data from this study indicate that progesterone in supraphysiological concentrations promotes apoptosis in HUVECs and activates p38 and JNK. A study in pregnant Sprague-Dawley rats showed an increase in the activity of caspases 2, 8 and 9 that corresponded to the peak concentration of progesterone in the pregnant females, resulting in an increase in the number of apoptotic cells in the ovary (23). Our assumption is in accordance with these results, in terms of the increase in apoptotic cells in the presence of progesterone. We reported for the first time that supraphysiological concentrations of progesterone are capable of increasing the phosphorylation of p38 and JNK. Upon the activation of JNK, c-jun, which is a component of transcription factor AP-1, is phosphorylated and activated, thus regulating a set of genes involved in apoptosis (24). The effects of the phosphorylation of p38 are similar to those of JNK (25), involving transcription factors and proinflammatory cytokines. Therefore, progesterone should induce apoptosis in HUVECs by activating p38 and JNK. We found no literature documenting the activation of p38 and JNK in HUVECs due to the action of progesterone. However, previous work in a breast cancer cell line (T47D-YB) showed that the incubation of these cells with R5020 (an 
analog of progestin) and EGF produced an increase in the phosphorylation of ERK1/2, p38 and JNK (26). Although the cells and the conditions used by Lange et al to visualize the activation of JNK and p38 by progesterone are different from those used in this study, their investigation provides additional evidence that the hormone has a direct action on the MAPK pathway.

It is known that testosterone promotes apoptosis in endothelial cell lines, with a reduction in the expression of Bcl-2 and an increase in the number of apoptotic cells $(27,28)$. The same phenomenon was observed in the present study, albeit at higher-than-physiological concentrations of the hormone. Perhaps the difference in the effect of concentrations resides in the choice of primary cultures or cell lines, and in the number of hormone receptors that each has. Shimada et al (29) observed that it was necessary to activate p38 and JNK for prostate cancer cells ( $\mathrm{LNCaP}$ ) incubated with dihydrotestosterone to enter into programmed cell death. This led us to hypothesize that, with an increase in the number of apoptotic cells after incubation with testosterone (or progesterone), JNK could be active in addition to p38. The results of this study confirm that supraphysiological concentrations of testosterone produce an increase in the phosphorylation of p38 and JNK.

In conclusion, the proliferative effect of estradiol on HUVECs occurs through an increase in the phosphorylation of ERK2, which is induced by the deprivation of serum. Furthermore, treatment with progesterone and testosterone at supraphysiological concentrations promotes apoptosis via the activation of p38 and JNK.

\section{Acknowledgements}

We are grateful to Dr A. Trevani and Dr R. Gamberale for their invaluable suggestions, and to Miss S.J. Torres for technical assistance. This work was supported by CONICET, SECyT, and the René Barón Foundation.

\section{References}

1. Karsan A and Harlan JM: Modulation of endothelial cell apoptosis: mechanisms and pathophysiological roles. J Atheroscler Thromb 3: 75-80, 1996.

2. Asai K, Kudej RK, Shen YT, et al: Peripheral vascular endothelial dysfunction and apoptosis in old monkey. Arterioscler Thromb Vasc Biol 20: 1493-1499, 2000.

3. Mallat Z, Benamer H, Hugel B, Benessiano J, Steg PG, Freyssinet JM and Tedgui A: Elevated levels of shed membrane microparticles with procoagulant potential in the periphera circulating blood of patients with acute coronary syndromes. Circulation 101: 841-843, 2000.

4. Okada M, Murase K, Makino A, Nakajima M, Kaku T, Furukawa S and Furukawa Y: Effects of estrogens on proliferation and differentiation of neural stem/progenitor cells. Biomed Res 29: 163-170, 2008 .

5. Hutchison SJ, Sudhir K, Chou TM, et al: Testosterone worsens endothelial dysfunction associated with hypercholesterolemia and environmental tobacco smoke exposure in male rabbit aorta. J Am Coll Cardiol 29: 800-807, 1997.

6. Ley R, Balmanno K, Hadfield K, Weston C and Cook SJ: Activation of the ERK $1 / 2$ signaling pathway promotes phosphorylation and proteasome-dependent degradation of the $\mathrm{BH} 3$ only protein. J Biol Chem 278: 18811-18816, 2003.

7. Deacon K, Mistry P, Chernoff J, Blank JL and Patel R: p38 mitogen-activated protein kinase mediates cell death and p21activated kinase mediates cell survival during chemotherapeutic drug-induced mitotic arrest. Mol Biol Cell 14: 2071-2087, 2003.
8. Putcha GV, Le S, Frank S, et al: JNK-mediated BIM phosphorylation potentiates BAX-dependent apoptosis. Neuron 38: 899-914, 2003.

9. Santen RJ, Song RX, McPherson R, Kumar R, Adam L, Jeng MH and Yue WJ: The role of mitogen-activated protein (MAP) kinase in breast cancer. Steroid Biochem Mol Biol 80: 239-256, 2002.

10. Weigel NL and Moore NL: Kinases and protein phosphorylation as regulators of steroid hormone action. Nucl Recept Signal 5: 1-13, 2007.

11. Watson CS and Lange CA: Steadying the boat: integrating mechanisms of membrane and nuclear-steroid-receptor signalling. EMBO Rep 6: 116-119, 2005.

12. Jaffe EA, Hoyer LW and Nachman RL: Synthesis of antihemophilic factor antigen by cultured human endothelial cells. J Clin Invest 52: 2757-2764, 1973.

13. Malich G, Markovic B and Winder C: The sensitivity and specificity of the MTS tetrazolium assay for detecting the in vitro cytotoxicity of 20 chemicals using human cell lines. Toxicology 124: 179-192, 1997.

14. Bakand S, Winder C and Hayes A: Comparative in vitro cytotoxicity assessment of selected gaseous compounds in human alveolar epithelial cells. Toxicol In Vitro 7: 1341-1347, 2007.

15. Vermes I, Haanen C, Steffens-Nakken H and Reutelingsperger C: A novel assay for apoptosis. Flow cytometric detection of phosphatidylserine expression on early apoptotic cells using fluorescein labelled annexin V. J Immunol Methods 184: 39-51, 1995.

16. Laemmli UK: Cleavage of structural proteins during the assembly of the head of bacteriophage T4. Nature 227: 680-685, 1970.

17. Kawagoe J, Ohmichi M, Tsutsumi S, Ohta S, Takahashi K and Kurachi H: Mechanism of the divergent effects of estrogen on the cell proliferation of human umbilical endothelial versus aortic smooth muscle cells. Endocrinology 148: 6092-6099, 2007.

18. Migliaccio A, Di Domenico M, Castoria G, De Falco A Bontempo P, Nola E and Auricchio F: Tyrosine kinase/p21 ${ }^{\text {ras }}$ / MAP-kinase pathways activation by estradiol receptor complex in MCF-7 cells. EMBO J 15: 1292-1300, 1996.

19. Singer CA, Figueroa-Masot XA, Batchelor RH and Dorsa DM: The mitogen-activated protein kinase pathway mediates estrogen neuroprotection after glutamate toxicity in primary cortical neurons. J Neurosci 19: 2455-2463, 1999.

20. Wade CB, Robinson S, Shapiro RA and Dorsa DM: Estrogen receptor (ER)alpha and ERbeta exhibit unique pharmacologic properties when coupled to activation of mitogen-activated protein kinase pathway. Endocrinology 142: 2336-2342, 2001.

21. Sengupta K, Banerjee S, Saxena NK and Banerjee SK: Thombospondin-1 disrupts estrogen-induced endothelial cell proliferation and migration and its expression is suppressed by estradiol. Mol Cancer Res 2: 150-158, 2004.

22. Juan SH, Chen JJ, Chen CH, et al: 17ß-estradiol inhibits cyclic strain-induced endothelin-1 gene expression within vascular endothelial cells. Am J Physiol Heart Circ Physiol 287: H1254-H1261, 2004.

23. Peluffo MC, Bussmann L, Stouffer RL and Tesone M: Expression of caspase- $2,-3,-8$ and -9 proteins and enzyme activity in the corpus luteum of the rat at different stages during the natural estrous cycle. Reproduction 132: 465-475, 2006.

24. Derijard B, Hibi M, Wu IH, et al: JNK1: A protein kinase stimulated by UV light and $\mathrm{Ha}$-Ras that binds and phosphorylates the c-Jun activation domain. Cell 76: 1025-1037, 1994.

25. Harper SJ and LoGrasso P: Signaling for survival and death in neurones: the role of stress-activated kinases, JNK and p38. Cell Signal 13: 299-310, 2001.

26. Lange CA, Richer JK, Shen T and Horwitz KB: Convergence of progesterone and epidermal growth factor signaling in breast cancer. Potentiation of mitogen-activated protein kinase pathways. J Biol Chem 273: 31308-31316, 1998.

27. Ling S, Dai A, Williams MRI, Myles K, Dilley RJ, Komesaroff PA and Sudhir K: Testosterone (T) enhances apoptosis-related damage in human vascular endothelial cells. Endocrinology 143: 1119-1125, 2002

28. D'Ascenzo S, Millimaggi D, Di Massimo C, et al: Detrimental effects of anabolic steroids on human endothelial cells. Toxicol Lett 169: 129-136, 2007.

29. Shimada K, Nakamura M, Ishida E, Kishi M and Konishi N: Roles of p38- and c-jun NH2-terminal kinase-mediated pathways in 2-methoxyestradiol-induced p53 induction and apoptosis. Carcinogenesis 24: 1067-1075, 2003. 